\title{
Dynamic analysis of runout correction in milling
}

\author{
E. Diez Cifuentes ${ }^{a, *}$, H. Pérez García ${ }^{b}$, M. Guzmán Villaseñor ${ }^{a}$, A. Vizán Idoipe ${ }^{c}$ \\ a Department of Mechanical Engineering, University of La Frontera, Temuco, Chile \\ b Deparbnent of Mechanical Engineering University of León, 24071 León, Spain \\ 'Depatment of Mechanical and Manufacturing Engineering. Tecintical University of Madrid, 28006 Madrid, Spain
}

\begin{abstract}
A B S T R A C T
Tool runout and its effects is an important area of research within modelling. simulation. and control of milling forces. Tool runout causes tool cutting edges to experience uneven forces during milling. This fact also affects tool life and deteriorates workpiece surface quality. In this article a procedure, in order to diminish the effects of tool runout. is presented. The procedure is based on chip thickness modification by means of the fast correction of the tool feed rate. Dynamic feed rate modification is provided by superposing our own design of a fast feed system driven by a piezoelectric actuator to the conventional feed drive of the CNC machine tool. Previously, a model of the dynamic behaviour of the system was developed to analyze the influence of fast feed rate modification on cutting forces. The model incorporates the piezoelectric actuator response as well as the structural dynamics of the tool and the designed Fast Feed Drive System (FFDS). Simulated and experimental results presented in this paper show the effectiveness and benefits of this new tool runout correction procedure.
\end{abstract}

Keywords:

Milling

Tool runout

Cutting force control

Piezoelectric actuator

\section{Introduction}

Milling is one of the most extended cutting processes due to its large field of application within automotive, aerospace, mould and die, and other industries. For more than one hundred years, modelling, simulation and control of cutting forces have been important research issues for researchers with the objective of improving aspects like workpiece surface quality, tool wear resistance or process stability. Nevertheless, there still exist interesting aspects in milling that need to be explored in depth to achieve a better understanding of the process.

Unlike other machining processes, milling is affected by several variables that make its modelling especially complex. Tool runout (radial and axial), uneven tooth positions, deformations and tool wear are characteristics affecting milling operations [1]. Among these characteristics, radial tool runout in end milling has received special attention from researchers, starting with the work published by Kline and DeVor [2], which focused on the effects of radial tool runout on cutting forces in end milling. Other researchers have studied how tool runout affects cutting geometiy in end milling [3| proposing equations to calculate chip thickness in the case of tool runout. The identification of simple eccentricity, produced when tool has a different rotation axis than the geometric axis, was studied by Liang and Wang, and Wang and Zheng [4,5] while Seethaler and Yellowley [6] focused

\footnotetext{
* Corresponding author.

E-mail address: ediez@etsii.upm.es (E. Diez Cifuentes).
}

on the identification of radjal runout on each cutting edge of the milling cutter.

Tool runout in milling processes can come from many sources. According to Bao and Tanse] [7], tool runout mainly depends on spindle and toolholder characteristics. On the other hand, Schmitz et al. [8] assigns more importance to errors depending on the radial position of the teeth on the cutter. According to Hekman and Liang [9|, precise measurement or control of the static and dynamic tool runout is rather complex. While static runout may come from spindle errors, thermal deformation, insert settings and tool dimensional errors, dynamic tool runout may arise from other sources such as cutting force variation, spindle and tool imbalance and non-uniform progression of tool wear. Important effects of tool runout in milling are the decrease of the milled surface quality and the increase in the radial and axial force variation [5], which may lead to shorter tool life under uneven wear conditions for each cutting edge.

More recently, research has been focused on the incorporation of tool runout in the analysis of the dynamic stability of the process, the quality of machined surfaces and the milling of curved surfaces. Insperger et al. [10| and Wan et al. [11] showed that the predicted stability diagram in absence of tool runout differs considerably from the diagram obtained when tool runout is considered. These investigations also claim that the mathematical background necessary to address the solution of regenerative milling equations is more complex when tool runout is considered. Arizmendi et al. [12] proposed a model for the prediction of the surface topography machined by peripheral milling in presence of tool runout. This research concluded that tool runout 


\begin{tabular}{|c|c|c|}
\hline \multicolumn{2}{|c|}{ Nomenclature } & \multirow{2}{*}{$\begin{array}{ll}K_{0} & \text { Constant gain. } \\
{[K]} & \text { Stiffness coefficients matrix of the system. } \\
m^{\text {rabie }}, c^{\text {tabie }}, k^{\text {rabb }} \text { Feed direction modal mass, damping and } \\
\text { stiffness coeficients of the worktable. }\end{array}$} \\
\hline \multicolumn{2}{|c|}{$a_{p} \quad$ Axial depth of cut. } & \\
\hline \multicolumn{2}{|c|}{$\begin{array}{l}a_{0} \text { Coefficient of the zero order term in the actuator } \\
\text { transfer function. }\end{array}$} & $\begin{array}{l}\text { stiffness coefficients of the worktable. } \\
\mathrm{m}_{x}^{\text {rool }}, c_{x}^{\text {tool }}, k_{x}^{\text {tool }} X \text {-axis modal mass, damping and stiffness }\end{array}$ \\
\hline \multirow{2}{*}{$a_{1}$} & $\begin{array}{l}\text { Coefficient of the first order term in the actuator } \\
\text { transfer function. }\end{array}$ & $\begin{array}{l}\text { coefficients of the cutting tool. } \\
\mathrm{m}_{y}^{\text {tool }}, \mathrm{c}_{y}^{\text {tool }}, k_{y}^{\text {rool }} Y \text {-axis modal mass, } \mathrm{d}\end{array}$ \\
\hline & $\begin{array}{l}\text { Coefficient of the second order term in the actuator } \\
\text { transfer function. }\end{array}$ & $\begin{array}{l}\text { coefficients of the cutting tool. } \\
{[M] \quad \text { Mass matrix of the system. }}\end{array}$ \\
\hline \multirow{7}{*}{$\begin{array}{l}{[C]} \\
D \\
f_{i} \\
F_{s, j} \\
F_{s} \\
\{F\} \\
\{\tilde{F}\}\end{array}$} & ig coefficients matrix of the system. & Spindle speed. \\
\hline & diameter. & Nominal tool radius. \\
\hline & l feed per tooth. & Tool radius at tooth $j$. \\
\hline & Tangential, radial and axial cutting forces, for $s=t, r, a$. & Time con \\
\hline & $X, Y$ and $Z$ components of cutting forces, for $s=X, Y, Z$. & nand to th \\
\hline & Cutting force vector of the system. & Position re \\
\hline & $\begin{array}{l}\text { Vector that represents piezoactuator action on the } \\
\text { worktable. }\end{array}$ & $\begin{array}{l}x_{\text {table }}, \dot{x}_{\text {rable }}, \ddot{x}_{\text {rabbe }} X \text {-axis displacement, velocity and acceleration } \\
\text { of the table. }\end{array}$ \\
\hline \multirow{2}{*}{$\begin{array}{l}G_{p a}(s) \\
h_{j}(\phi)\end{array}$} & $\begin{array}{l}\text { Transfer function of the actuator-drive-control sys- } \\
\text { tem. }\end{array}$ & $\begin{array}{l}x_{\text {tool }}, \dot{x}_{\text {tool }}, \ddot{x}_{\text {tool }} X \text {-axis displacement, velocity and acceleration } \\
\text { of the tool. }\end{array}$ \\
\hline & $\begin{array}{l}\text { Uncut chip thickness without dynamic effects for } \\
\text { tooth } j \text {. }\end{array}$ & $\begin{array}{c}y_{\text {tool }}, \dot{y}_{\text {rool }}, \ddot{y}_{\text {tool }} \text { Y-axis displacement, velocity and acceleration } \\
\text { of the tool. }\end{array}$ \\
\hline \multirow{3}{*}{$\begin{array}{l}h_{r o}^{j} \\
h_{d}(t) \\
k_{s}\end{array}$} & $\begin{array}{l}\text { Chip thickness deviation due to cutter radial runout } \\
\text { for cutting edge } j \text {. }\end{array}$ & $\begin{array}{c}\{X\},\{X\},\{X\} \text { Position, velocity and acceleration vectors describ- } \\
\text { ing the movement of the system. }\end{array}$ \\
\hline & Uncut chip thickness including dynamic effects. & Cutter rotatio \\
\hline & $\begin{array}{l}\text { Tangential, radial and axial cutting force coefficients, } \\
\text { for } s=t, r, a \text {. }\end{array}$ & $\begin{array}{l}\text { Entry angle of cutting edge } j \text {. } \\
\text { Exit angle of cutting edge } j \text {. }\end{array}$ \\
\hline$k_{0}, m$ & $\begin{array}{l}\text { Cutting parameters depending on workpiece material } \\
\text { and cutting tool for tangential direction. }\end{array}$ & \\
\hline
\end{tabular}

and spindle tilting have a strong influence on the heterogeneity bands produced on the milled surface. On the other hand, Desai et al. [13| showed that when milling curved surfaces, tool tunout plays an important role because it changes the interaction between the trajectories of the cutting teeth.

One way to reduce the unwanted effects on milling processes would be through the use of systems allowing the correction of the cause for tool runout. In this sense, some papers have been published dealing with the modification of uncut chip thickness to improve milling processes. Liang and Perry [14] proposed chip load compensation for the elimination of cutting force oscillations due to cutter runout. This correction was based on the control of the spindle frequency force component, since this component includes all the effects of runout on cutting forces, as various researchers have pointed out in previous articles $[4,5]$. This method is very effective, but the control time may be a limit at higher spindle speeds. This limitation could be solved if the evolution of milling forces, when the piezoelectric actuator is valying the chip load, is better understood. As a result, with an adequate command signal to the piezoelectric actuator, it is possible to deal with higher spindle speeds. Another approach to compensate radjal runout in face milling was presented by Sastry et al. [15]. The compensation was based on the continuous variation of the spindle speed in a sinusoidal pattern. It was shown that this methodology reduced the effect of tool runout on the cutting force pattern considerably and the surface profile was improved. However, using a sinusoidal pattern to vary spindle speed would be the solution when runout comes only from tool eccentricity. In the field of simulation, a dynamic model in order to simulate a process controller for end milling was presented by Kolartis and DeVries [16]. The model is able to predict cutting forces and surface profile error under changes of feed rate and other cutting conditions.

This article focuses on the procedures developed to diminish the runout effect on milling processes based on dynamic correction. This correction is carried out by means of the use of piezoelectric actuators working in parallel with the feed drive system of a conventional $\mathrm{CNC}$ machine tool. The presented analysis emphasizes the study of tool and feed system dynamics, and how these elements affect the behaviour of force control.

\section{Cutting force control in milling tools with runout}

Tool runout causes chip thickness to vary over the tool rotation and therefore the tool experiences uneven forces during each cutting tooth period. The objective of runout correction is to diminish this effect by means of feed rate modification, making each cutting edge carry the same chip load.

In this study, feed rate modification is carried out using a Fast Feed Drive System (FFDS) driven by a piezoelectric actuator. The FFDS is superposed on the conventional machine tool feed drive system. This combined feed drive system scheme is similar to that presented by Elfizi et al. [17] and Perez et al. [18|. It is well known that piezoelectric based FFDSs have higher dynamic response and better resolution than conventional feed drive systems. However, its application on machine tools has been restricted due to its limited range for linear displacements. Combined feed drive systems allow micrometric changes in the working table position at high frequency over a large field of displacement.

The controlled movement of the FFDS to modify feed rate is determined directly from measured forces based on the relationship between uncut chip thickness and cutting forces according to the cutting force model presented in the next section of this atticle.

\subsection{The curting farce madel}

Several papers have been published dealing with cutting force modelling including the effects of tool runout $[2,7,16,19-21]$ 
where other issues that may affect the simulation process have also been considered such as the real tool trajectory, the use of microtools and the modification of the exit and entry angles. The main contribution of the present paper is to analyze the effect of including a piezoactuator on cutting force control. In order to simulate the cutting forces in a milling process, a mechanistic cutting force model was employed. Cutting forces were calculated based on the cutting geometry engaged into the workpiece and the empirical equations that relate the cutting forces with the uncut chip thickness. The trajectory of the cutting tool was approximated by a circular path, thus the chip thickness including tool runout can be calculated as

$h_{j}(\phi)=f_{t} \sin (\phi)+h_{r o}^{j}$

where $h_{r o}^{j}$ is the variation of the chip thickness due to runout in cutting edge $j$, and can be calculated as follows:

$h_{r o}^{j}=\rho_{j}-\rho_{j-1}$

The relationship between variables involved in calculating the static chip thickness for a tool considering runout can be seen in Fig. 1 . The runout of cutting edge, $\rho_{j}$, represents the variation of the effective radius of each flute which results in a variation on cutting forces. The effective radius is the radius of the actual trajectory of the flute, which differs from its nominal radius due to runout. This parameter takes into account errors coming from different sources such as tool eccentricity,

$\mathbf{a}$

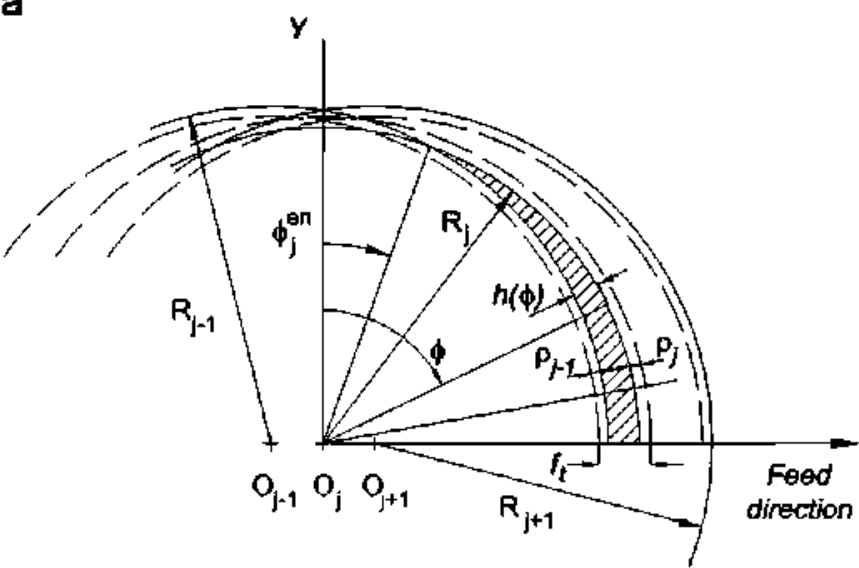

b

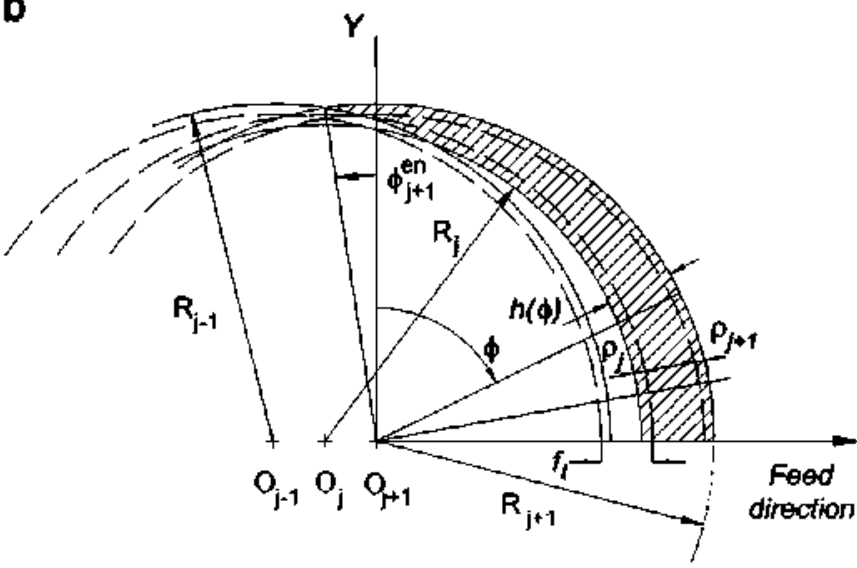

Fig 1. Geometry for the cutting forces calculation: (a) the smaller ellective radius is cutting and (b) the bigger ellective radius is cutting. Segmented line represents tool trajectory without runout. dimensional errors of the cutting edges and spindle tilting. Due to the difficulty of measuring tool runout precisely, in this paper $h_{\text {ro }}^{j}$ is calculated indirectly from the measured cutting forces acting on each flute.

Since tool runout is significantly affected by the eccentricity of tool-tool holder-spindle assembly, researchers usually relate tool runout to eccentricity, using for the eccentricity definition two parameters, its magnitude and its angular position referring to a reference flute. In this case, the effective radius varies along the cutting edge. In addition, this definition excludes other possible causes for error.

In this study, where small values of depth of cut and helix angles were considered, the variation of the effective radius along the cutting edge may be neglected and then the tool runout can be adequately defined by means of the difference between the actual and the nominal trajectory for each flute.

Considering the specific cutting force as a potential function of chip thickness, tangential, radial and axial cutting forces along the cutting edge can be calculated using Eq. (3).

$F_{s, j}(\phi)=k_{s}\left(h_{j}\right) h_{j}(\phi) a_{p}, \quad s=t, r, a$

Cutting force coefficients in tangential, radial and axial directions are expressed as a potential function of the instantaneous chip thickness. For tangential direction

$k_{t}\left(h_{j}\right)=k_{t 0}\left(h_{j}\right)^{-i n}$

Thus for tangential direction, Eq. (3) can be written as

$F_{r, j}(\phi)=k_{i 0}\left(h_{j}\right)^{1-i n} a_{p}$

In a similar way, equations can be obtained for the other two directions.

Tangential, radial and axial forces are projected in $X, Y$ and $Z$ directions, according to the following transformation:

$\left[\begin{array}{l}F_{X, j}(\phi) \\ F_{Y, j}(\phi) \\ F_{Z, j}(\phi)\end{array}\right]=\left[\begin{array}{lll}-\cos (\phi) & -\sin (\phi) & 0 \\ \sin (\phi) & -\cos (\phi) & 0 \\ 0 & 0 & 1\end{array}\right]\left[\begin{array}{l}F_{t, j}(\phi) \\ F_{r, j}(\phi) \\ F_{a, j}(\phi)\end{array}\right]$

The result of the contribution of all cutting edges in the total force acting on the tool in $X, Y$ and $Z$ axes is given in Eq. 7 .

$F_{s}(\phi)=\sum_{j=1}^{N} F_{s, j}, \quad s=X, Y, Z$

\subsection{The dynamic model and force control in milling}

A regenerative milling model was used to describe the dynamic behaviour of the milling process [22-28|. A dynamic milling model is proposed that includes a system with two degrees of freedom for the tool and a system with one degree of freedom for the FFDS, which coincides with feed direction. The effect of piezoelectric actuator movement on the milling forces is calculated by means of the regenerative cutting force model, where the uncut chip thickness depends on tool and workpiece vibration, which is caused mainly by the controlled oscillations of the piezoelectric actuator. Fig. 2 shows the FFDS designed to correct tool runout effects and the associated model including actuator system dynamics. From this model, the force diagrams and the signals acting on each element were determined in order to obtain the equations that model the problem. These diagrams can be seen in Fig. 3.

The resulting equations that model the system are shown in Eq. (8)

$[M]\{\ddot{X}\}+[C]\{\dot{X}\}+[K]\{X\}=\{F\}+\{\tilde{F}\}$

where $[M],[C], y[K]$ are diagonal matrices, $\{F\}$ is the cutting force vector and $\{\tilde{F}\}$ represents the action of the piezoelectric 


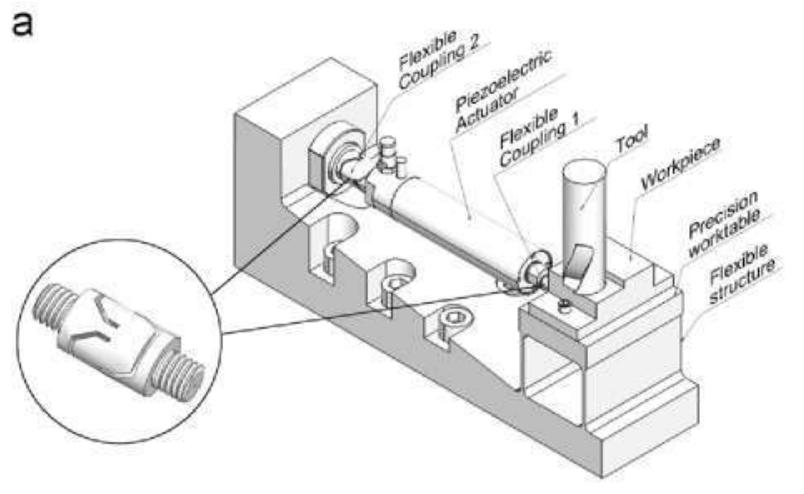

b

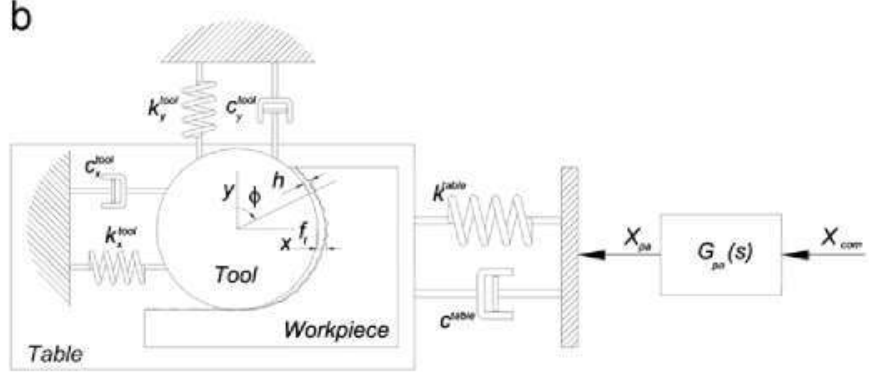

Fig. 2. (a) Fast feed drive system designed to control tool runout and (b) the corresponding dynamic model.

a

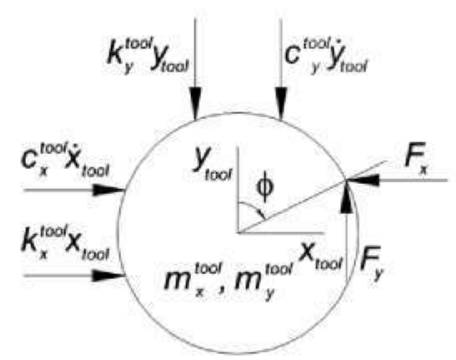

b

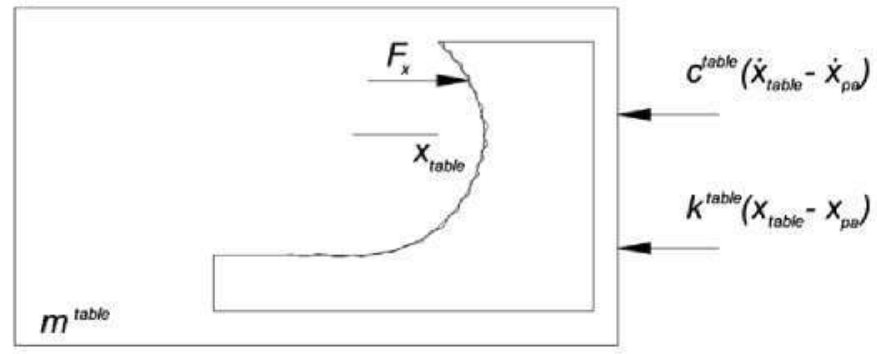

C

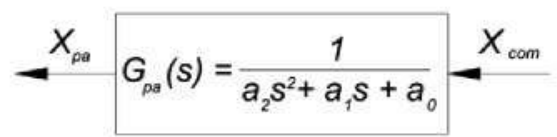

Fig. 3. Forces diagram acting on (a) the tool and (b) the table, and (c) diagram of signals acting on the system actuator-drive-control.

actuator on the table

$[M]=\left[\begin{array}{cccc}m_{x}^{\text {tool }} & & & \\ & m_{y}^{\text {tool }} & & \\ & & m_{x}^{\text {table }} & \\ & & & a_{2}\end{array}\right] ;\{\ddot{X}\}=\left\{\begin{array}{l}\ddot{x}_{\text {tool }} \\ \ddot{y}_{\text {tool }} \\ \ddot{x}_{\text {table }} \\ \ddot{x}_{p a}\end{array}\right\}$
$[C]=\left[\begin{array}{cccc}c_{x}^{\text {tool }} & & & \\ & c_{y}^{\text {tool }} & & \\ & & c^{\text {table }} & \\ & & & a_{1}\end{array}\right] ;\{\dot{X}\}=\left\{\begin{array}{l}\dot{x}_{\text {tool }} \\ \dot{y}_{\text {tool }} \\ \dot{x}_{\text {table }} \\ \dot{x}_{p a}\end{array}\right\}$

$[K]=\left[\begin{array}{cccc}k_{x}^{\text {tool }} & & & \\ & k_{y}^{\text {toot }} & & \\ & & k^{\text {table }} & \\ & & & a_{0}\end{array}\right] ;\{X\}=\left\{\begin{array}{l}x_{\text {toot }} \\ y_{\text {toot }} \\ x_{\text {table }} \\ x_{p a}\end{array}\right\}$

$\{F\}=\left\{\begin{array}{c}F_{x} \\ F_{y} \\ F_{x} \\ 0\end{array}\right\}$

$\{\tilde{F}\}=[C]\left\{\begin{array}{l}0 \\ 0 \\ \dot{x}_{p a} \\ 0\end{array}\right\}+[K]\left\{\begin{array}{l}0 \\ 0 \\ x_{p a} \\ 0\end{array}\right\}+\left\{\begin{array}{l}0 \\ 0 \\ 0 \\ x_{c o m}\end{array}\right\}$

$F_{x}$ and $F_{y}$ are defined by Eq. (7). The dynamic structural parameters of the cutting tools and the FFDS were determined by experimental modal analysis. The dynamic parameters of the response of the piezoelectric actuator, the drive and controller were obtained by means of a procedure for system identification. These procedures are described in the next section of this article. Considering tool flexibility and the feed rate variation due to the piezoelectric actuator, regenerative action causes Eq. (1) to be dependent on tool and workpiece vibration. This situation is modelled using delayed differential equations. If an ideal case is presented where the tool has equally spaced flutes and the runout is negligible, the delay present in the differential equations will be constant. However, when tool runout is considered, the delay becomes time dependent, due to the small variation produced at the entry and exit angles for each cutting edge $[10,11,29,30]$. In addition, it was considered that tool and workpiece vibration levels do not affect the delay. Information related to solving these equations can be found in Ref. [31]. In the present paper the following aspects were taken into account relating to this matter:

- All simulations and experiments were carried out using 2 flute/ insert milling tools. The model is oriented to small diameter tools where two flutes is more common. For the case of small width of cut, the number of flutes simultaneously cutting is less than the number of cutting edges of the tool.

- Both static and dynamic runout were lesser than the nominal feed rate per tooth.

- The variation of entry and exit angles due to runout was considered in simulation.

Previous assumptions allow us to be sure that there will be a maximum of two delays in each tool revolution. In addition, based on these assumptions, it can be observed that for the main part of the cutting zone, the delay that defines the regenerative effect of the milling operation will be equal to half of the tool rotation period. Moreover, at the entry and exit of the cutting edge with a bigger effective radius, there will be a tiny cutting zone where the delay will be equal to the cutting tool rotation period. This means that for the flute/insert with the bigger effective radius there will be zones at entry and exit where the cutting edge will remove material left by the cutting edge itself during the previous tool revolution (delay equal to the tool rotation period) but there will be another zone where the cutting edge will remove material left 
by the previous flute/insert (delay equal to half of the tool rotation period).

The inclusion of all effects previously mentioned causes chip thickness in Eq. 1 to be time dependent. Then the expression for the chip thickness, which includes tool runout and dynamic effects is as shown in Eq. 14.

$$
\begin{aligned}
h_{d}(t)= & {\left[f_{t}-x_{\text {tool }}(t)+x_{\text {tool }}(t-\tau(t))-x_{\text {table }}(t)+x_{\text {rable }}(t-\tau(t))\right] \sin [\phi(t)] } \\
& +\left[-y_{\text {toot }}(t)+y_{\text {toot }}(t-\tau(t))\right] \cos [\phi(t)]+h_{\text {ro }}(t)
\end{aligned}
$$

\subsection{Characterization of the milling force control system}

In this part of the article, the characterization of the proposed system is presented. Firstly, some design details of the FFDS and the experimental determination of its dynamic parameters are pointed out. Secondly, technical data of the piezoelectric actuator used are presented and the system identification procedure for the piezoelectric actuator, the drive and the controller is explained. Finally, the identification of tool characteristics is described.

\subsubsection{The fast feed drive system}

The FFDS designed to carry out runout correction is made up of a worktable, a pair of flexible couplings, a flexible structure, and a piezoelectric actuator which provides the rapid movement to the table, as is shown in Fig. 2. In order to obtain an accurate performance of the FFDS, some important issues were taken into account in the design of the mechanical system, as described below:

- The use of flexure joints to eliminate friction and to minimize backlash.

- High stiffness of the base structure to avoid undesirable deformations.

- The use of appropriate flexible couplings to avoid tilting and shearing forces, which may damage the actuator.

Simulations based on the Finite Element Method, which are not presented here, were performed in order to check the mechanical behaviour of the system designed. The FFDS structure, including worktable, couplings and the actuator structure, was modelled as a one degree of freedom system. The structural dynamic response was determined by means of experimental modal analysis. The system response was measured with a modal accelerometer attached to the worktable of the FFDS. Both the experimental and

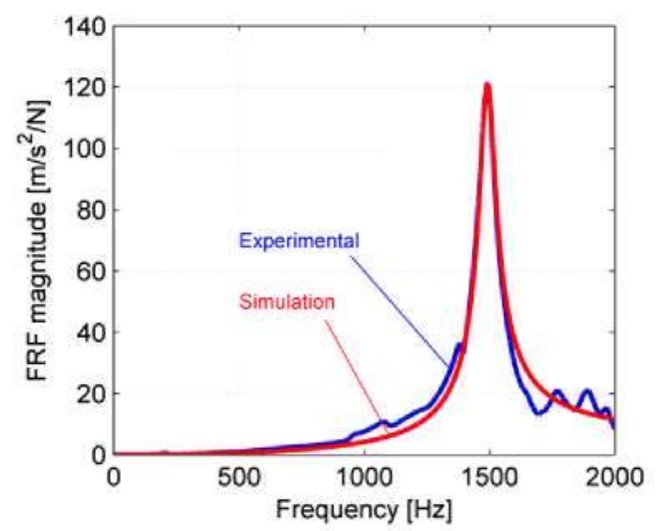

Fig. 4. Amplitude of the FFDS frequency response function in the feed direction. fitted frequency response functions are shown in Fig. 4, while the modal parameters extracted are shown in Table 1.

\subsubsection{Piezoelectric actuator, drive and position control loop}

The piezoelectric actuator employed to drive the FFDS was a P-212.4S from Physik Instrumente. This model is able to provide a push/pull force of $2000 / 300 \mathrm{~N}$ and a maximum displacement of $60 \mu \mathrm{m}$. The static stiffness of the actuator is $34 \mathrm{~N} / \mu \mathrm{m}$. The dynamic performance of the actuator is strongly influenced by both the available power of the drive used and the control strategy employed to control its position [32]. The drive used to feed the actuator was the E-471 high power amplifier from Physik Instrumente. In order to control its position, the actuator was operated in closed loop mode. In this way a higher dynamic stiffness is achieved as well as a better dynamic response. At the same time, hysteresis is minimized and can be overlooked in the movement range used for the purposes for this study. Although piezoelectric actuator system behaviour is complex and relates voltage/current inputs with position/force outputs, some simplifications may be assumed depending on the actuator setup (preload) and the operating conditions. In this case, the actuator is operated at a load level significantly lower than the maximum load level that it can bear, hence a linearity condition between the command signal and the actuator response can be supposed regardless of the dynamic forces acting on it.

The parameters governing the dynamic behaviour of the actuator were estimated from the experimental identification of the transfer function of the actuator, its drive and its position control loop. The input signal considered for the identification process was a position command, a step signal with $6 \mu \mathrm{m}$ in amplitude. The output of the system was the position of the actuator measured with its own strain gauge system. The transfer function of the system was fitted to a transfer function with two real poles. The general form of the transfer function for this system is shown in Eq. 15.

$G_{p a}(s)=\frac{X_{p a}(s)}{X_{c o m}(s)}=\frac{K_{0}}{\left(1-T_{1} s\right)\left(1-T_{2} s\right)}$

The estimated parameters characterizing the dynamic behaviour of the actuator, its drive and controller are shown in Table 2.

From the data presented in Table 2, the coefficients $a_{0}, a_{1}$ and $a_{2}$ modelling the dynamics of the actuator (shown in Fig. $3 \mathrm{c}$ ) were calculated and the obtained result is

$a_{0}=\frac{1}{K}$

$a_{1}=\frac{T_{1}+T_{2}}{K}$

Table 1

Modal parameters adjusted for the FFDS structure response.

\begin{tabular}{lll}
\hline$m^{\text {table }}[\mathrm{kg}]$ & $k^{\text {table }}[\mathrm{N} / \mathrm{m}]$ & $c^{\text {table }}[\mathrm{Ns} / \mathrm{m}]$ \\
\hline 0.194 & $1.7 \mathrm{E} 7$ & 77.3 \\
\hline
\end{tabular}

Table 2

Estimated parameters modelling the dynamic behaviour of the actuator, its drive and controller.

\begin{tabular}{ccc}
\hline $\boldsymbol{K}_{0}$ & $\boldsymbol{T}_{1}$ & $\boldsymbol{T}_{2}$ \\
\hline 0.99536 & 0.0011303 & 0.0011376 \\
\hline
\end{tabular}


$a_{2}=\frac{T_{1} T_{2}}{K}$

\subsubsection{Cutting tool}

The dynamic response of the tool can be studied when the frequency response function, measured at the tool tip, is known. In this study, frequency response function was obtained by means of experimental modal analysis. The excitation was achieved using a modal impact hammer, while the response was measured with a small size accelerometer. Force and acceleration signals were measured using a data acquisition system and later processed with our own modal analysis software to obtain the frequency response functions and the modal parameters of the predominant mode. As shown in Fig. 5, frequency response functions for each axis of the tool are very similar, thus the same fitting was used for both directions. The adjusted values for the natural frequency, around $900 \mathrm{~Hz}$, are shown in Table 3 .

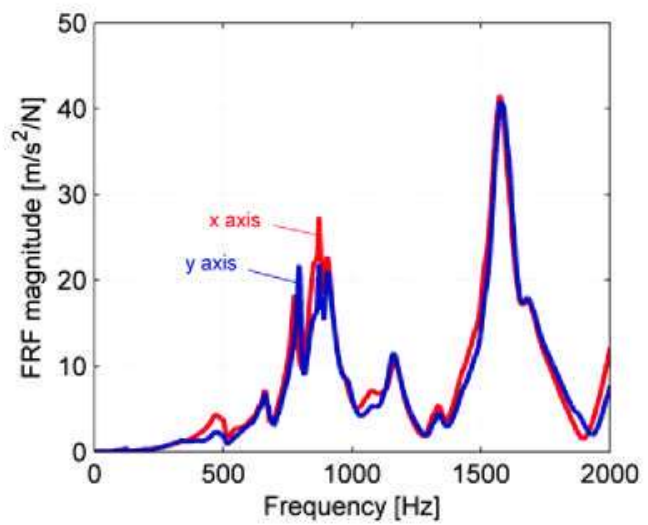

Fig. 5. Magnitude of the frequency response functions at tool tip for $X$ and $Y$ axes.

Table 3

Dynamic parameters fitted for one of the tools used in the experiments. $D=25 \mathrm{~mm}$

\begin{tabular}{lllllll}
\hline Diameter $[\mathrm{mm}]$ & $L / D$ & Type & Inserts & $m[\mathrm{~kg}]$ & $k[\mathrm{~N} / \mathrm{m}]$ & $c[\mathrm{Ns} / \mathrm{m}]$ \\
\hline 25 & 3.8 & Insert & 2 & 0.3641 & $9.67 \mathrm{E}+06$ & 244
\end{tabular}

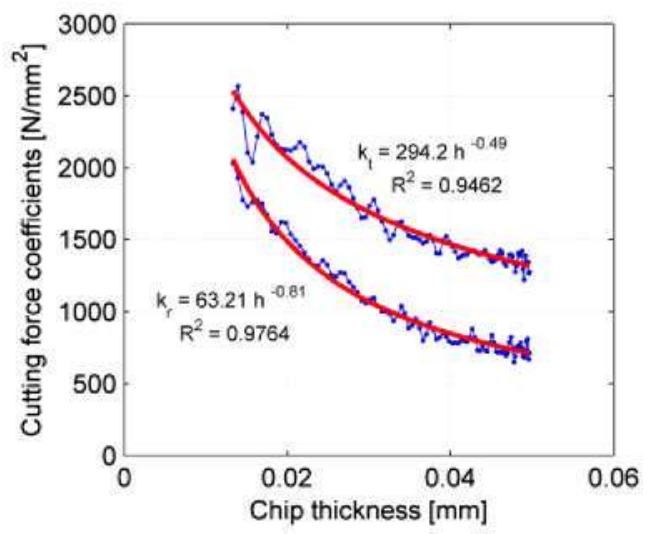

Fig. 6. Fitted values for $k_{t}$ and $k_{r}$.

\section{Experimental and simulation results}

In order to determine milling parameters, a procedure similar to that presented in [33] was followed. $K_{t}$ and $k_{r}$ were considered to be potential functions of chip thickness along the cutting zone. The material used in all the cutting tests was AL-7040. The potential fitted functions for specific cutting forces are shown in Fig. 6 (for $8 \mathrm{~mm}$ diameter, $f_{t}=0.05 \mathrm{~mm} /$ tooth, $a_{p}=1 \mathrm{~mm}$, $N=1200 \mathrm{rpm}$ ).

The control strategy was implemented in LabVIEW 8.2. Command signal generation, control and data acquisition tasks were carried out using the $\mathrm{NI} \mathrm{PCl} 6251$ high speed data acquisition device. Fig. 7 shows the layout of the experimental setup. The command signal to the actuator $x_{\text {com }}$ was synchronized with tool rotation. In this way it is possible to control the entry of each flute into the cutting zone. The reference pulse for the control was generated in each tool revolution and it was measured using an optic sensor. From the reference pulse, a controllable delay pulse was generated, which coincided with the entry in the cutting zone. The command signal $x_{\text {com }}$ had the same frequency as tool rotation and its amplitude was determined by the difference between the cutting forces by estimating $h_{\text {ro }}^{j}$ for each flute. The FFDS was placed on a dynamometric table to measure cutting forces on $X, Y$ and $Z$ axes. Additionally, the table position was measured directly by using a laser interferometer to verify table movement $x_{\text {table }}$.

In order to evaluate the effectiveness of runout control, several milling tests were conducted with various tools ranging from 25 to $8 \mathrm{~mm}$ in diameter. Fig. 8a shows measured and simulated cutting forces for the $25 \mathrm{~mm}$ tool used in the study. The amplitude variation in $F_{y}$ for each cutting edge, due to tool runout, can be seen in both simulation results and experimental measurements. Fig. $8 \mathrm{~b}$ shows experimental and simulation results when the runout control strategy was operating. The control action can be seen to modify the cutting force pattern, causing the $F_{y}$ amplitude to become the same for each cutting edge. According to experimental results obtained in this research and other works cited previously, runout in large diameter milling tools might not be an important issue because its magnitude is much lower than feed per tooth. However, runout is a serious drawback for milling tools with a smaller diameter because tool fabrication errors and clamping errors are more significant in this case.

The effectiveness of runout control and its effect on cutting forces was evaluated using an $8 \mathrm{~mm}$ tool. In this case the static tool runout was measured in the direction of feed rate, reaching a value of $20 \mu \mathrm{m}$ in diameter. Fig. 9a shows the measured and simulated cutting forces for the tool with runout. A difference in amplitude of $38 \%$ between the cutting forces for each flute, due to runout, can be observed. The corrected cutting forces can be seen in Fig. 9b. It can be observed that, despite the large amount of runout, the control is able to correct the undesirable effect of runout on cutting forces.

Fig. 10 is useful in evaluating the FFDS performance to control runout effects in milling. Experimental (Fig. 10b) and simulation (Fig. 10a) results are presented for the command position signal, actuator response, and worktable position measured with a laser sensor. Despite the influence of the cutting forces disturbing the dynamic system formed by the FFDS, this effect is almost unnoticeable on the control performance, as shown in Fig. 9.

In Fig. 10, the required command signal to correct tool runout was $30 \mu \mathrm{m}$ in amplitude. On the other hand, the fitted value of $h_{\text {ro }}^{j}$ obtained from measured cutting forces was $26 \mu \mathrm{m}$. Accordingly, the prediction of tool runout was precise enough to allow good cutting force estimation. In addition, if these values of tool runout are compared to measured static tool runout, a larger difference is 
FAST FEED DRIVE SYSTEM (FFDS)

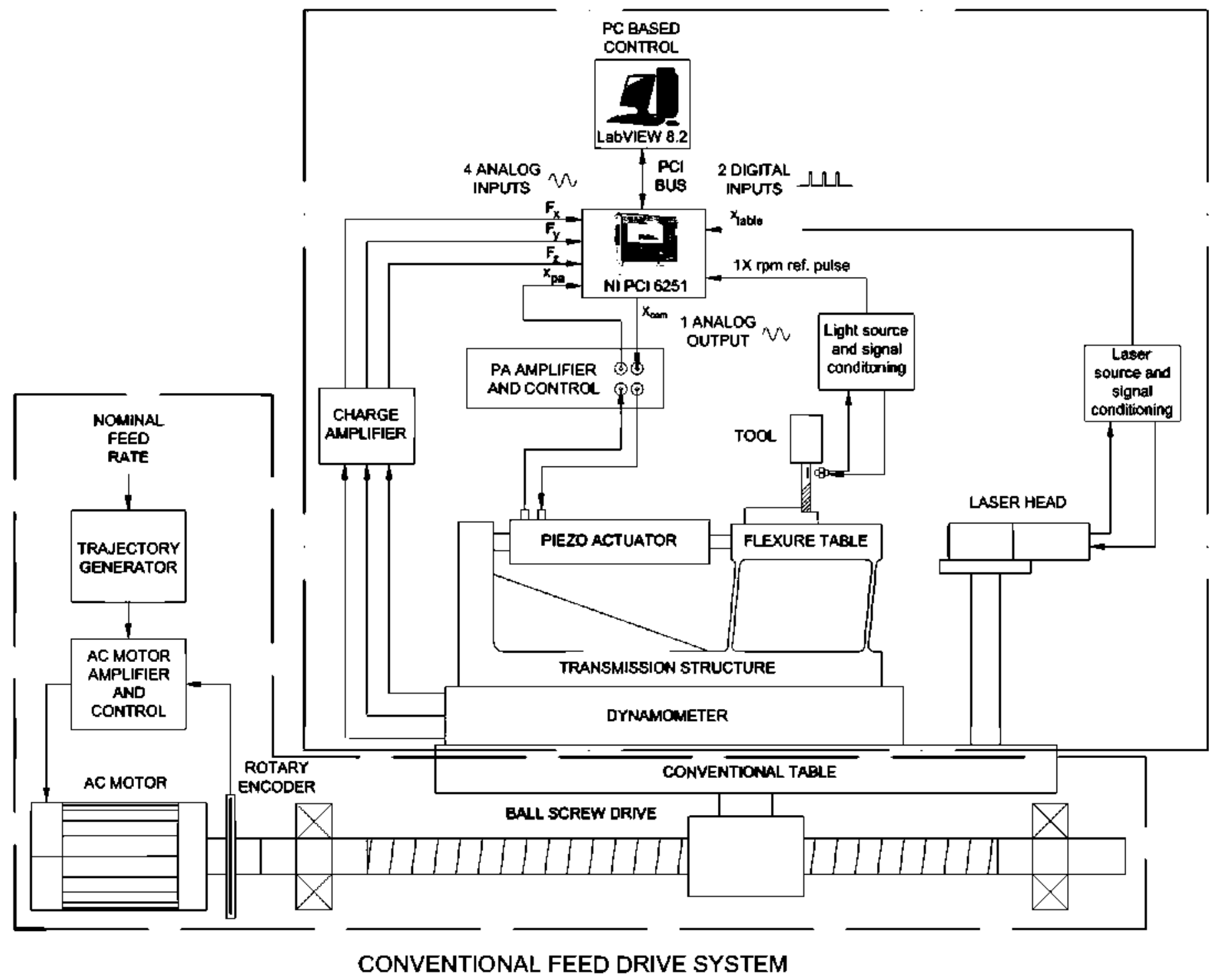

Fig 7. Experimental setup.

observed. This difference, between static and dynamic tool runout, can be attributed to the non-inclusion, in static measurements, of several aspects affecting tool runout, such as uneven tooth spacing or dynamic effects. The same observation was reported by Wang and Zheng [5].

In Fig. 10 both the actuator and the FFDS follow the command signal $x_{\text {com }}$ showing deviations lower than $10 \%$ for simulation, and even sinaller for experimental results. For slot milling experiments, the differences between the command signal and table position were greater at the entry and exit of the tool. The influence of these deviations on control effectiveness is not significant because chip thickness is relatively small at the entry and exit angles. Simulation and experimental results show that for the frequency range considered in this research, a second order model fits the piezoelectric actuator and its dynamic response adequately.

Regarding the control procedure, the spindle speed limit was imposed mainly by the dynamic response of the piezoelectric actuator and its position control loop. In this article, the experiments were carried out at a spindle speed of $1200 \mathrm{rpm}$. The use of an elastic stiucture to provide table displacement and a command signal at the spindle rotation frequency allowed the control at higher frequencies rather than using other approaches.

\section{Conclusions}

In this article, a cutting force control in order to correct tool runout has been presented. The main conclusions of this work can be summarized as follows:

1. The cutting force model with fast feed rate modification: A cutting force model to investigate the influence of feed rate modification on cutting forces in milling, using delayed differential equations, was developed. Mechanistic cutting force modelling was used to predict cutting forces considering 
a

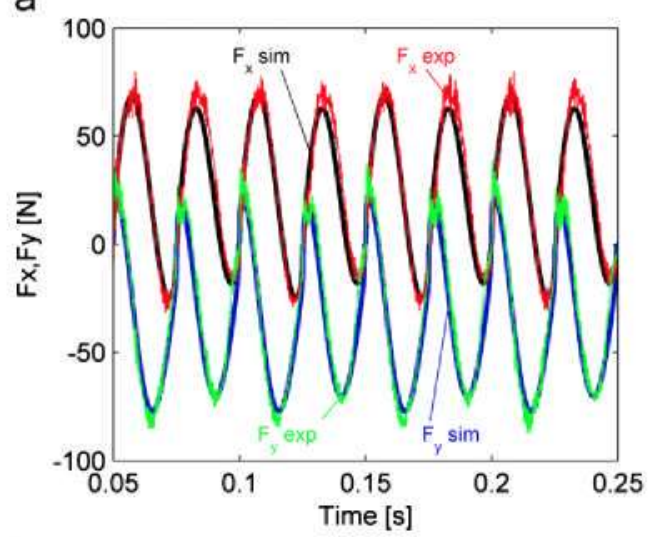

b

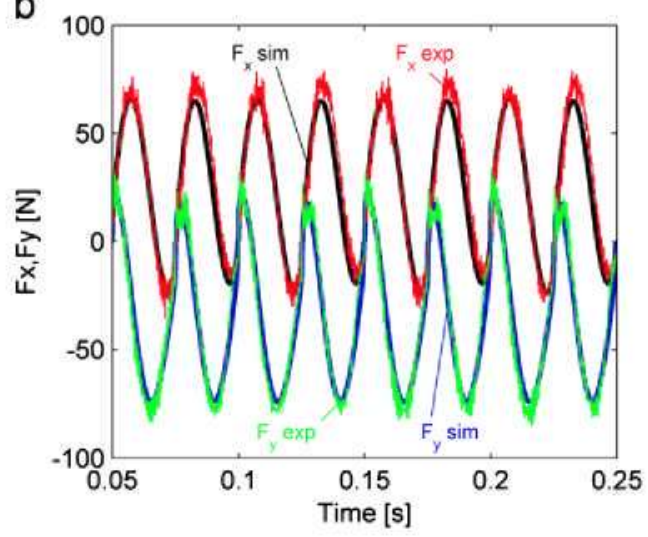

Cutting conditions:

$\begin{array}{ll}\mathrm{D}=25 \mathrm{~mm} & \mathrm{f}_{\mathrm{t}}=0.05 \mathrm{~mm} / \text { tooth } \\ \mathrm{N}=1200 \mathrm{rpm} & \mathrm{h}_{\mathrm{ro}}=4 \mu \mathrm{m} \\ \mathrm{a}_{\mathrm{p}}=1 \mathrm{~mm} & \end{array}$

Fig. 8. Cutting forces for the $25 \mathrm{~mm}$ tool: (a) without correction and (b) with correction.

the presence of tool runout. Tool runout, calculated indirectly from cutting forces, is characterized by means of a single parameter which represents the difference between the chip thicknesses on each tool flute. This parameter was found to be effective in the correction of tool runout when reduced depths of cut and small helix angles are used. The dynamic character of the process was taken into account by considering the dynamic response of both the tool and the system designed to modify the feed rate. Simulating the process, the controlled feed rate variation was found not to produce a decline in the efficiency of the process and that the tool responded correctly to fast changes in feed rate. Simulation permitted, prior to FFDS construction, the possible correction of cutting forces through feed rate variation proportional to tool runout.

2. Force correction methodology: The aim of this force control is to vary cutting forces so that each flute cuts the same amount of material. This strategy is based on feed rate variation in order to modify chip thickness. Using numerical simulation, the results proved to be very good. The dynamic characteristics of the tool, stiffness and damping, do not affect the cutting capacity of each flute negatively. For tools of low stiffness, it is possible not to reach the desired correction of chip thickness in order to obtain the same cutting capacity a

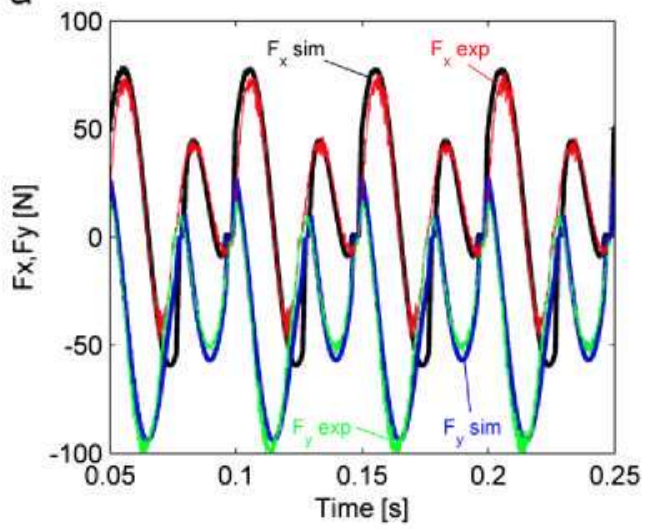

b

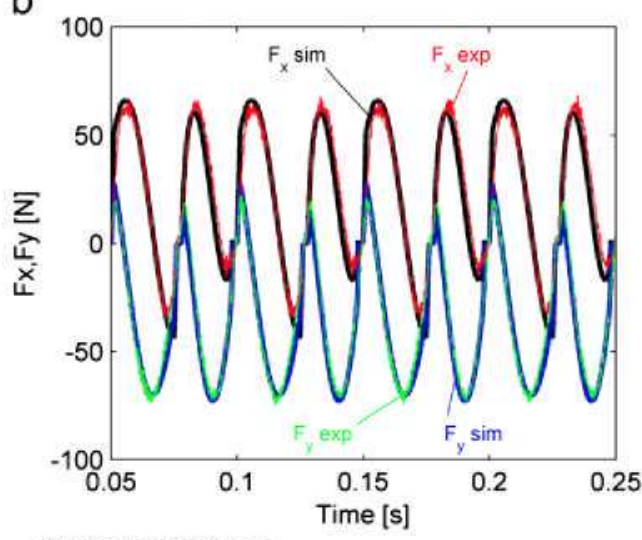

Cutting conditions:

$\begin{array}{ll}\mathrm{D}=8 \mathrm{~mm} & \mathrm{f}_{\mathrm{t}}=0.05 \mathrm{~mm} / \text { tooth } \\ \mathrm{N}=1200 \mathrm{rpm} & \mathrm{h}_{\mathrm{ro}}=26 \mu \mathrm{m} \\ \mathrm{a}_{\mathrm{p}}=1 \mathrm{~mm} & \end{array}$

Fig. 9. Cutting forces for the $8 \mathrm{~mm}$ tool: (a) without correction and (b) with correction.

for each flute. In this sense, experimental results performed with $3 \mathrm{~mm}$ tools, which are not shown in this paper, revealed that the application of this correction procedure is possible.

3. Experimental verification: In order to vary the fast feed rate, a feed drive system with a time response, comparable to the tool rotation frequency, was needed. Accordingly, a fast feed system driven by a piezoelectric actuator was designed and constructed. Although the piezoelectric actuator has a high dynamic response, its load capacity is restricted. This limitation restricts the use of these kinds of actuators.

The required feed rate modifications involve micrometric actuator displacements, thus it is necessary to design a feed drive system with micrometric resolution. This makes the use of an elastic-type transmission, to provide the modification of fast tool feed rate, necessary.

It was shown that the designed and constructed FFDS is able to correct the effect of tool runout on cutting forces, as the measured cutting forces in Section 3 of the paper show. By means of actuator displacement and worktable displacement measurements, it was shown that deviations from the command signal to the actuator were higher at the entry and exit angles, where the influence on cutting forces is smaller. 
a

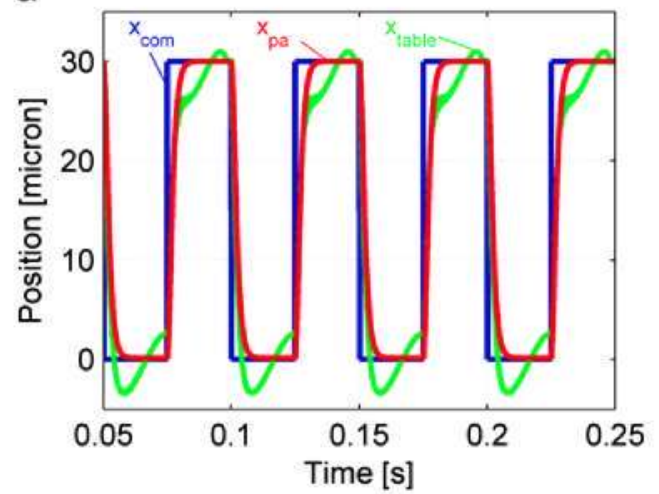

b

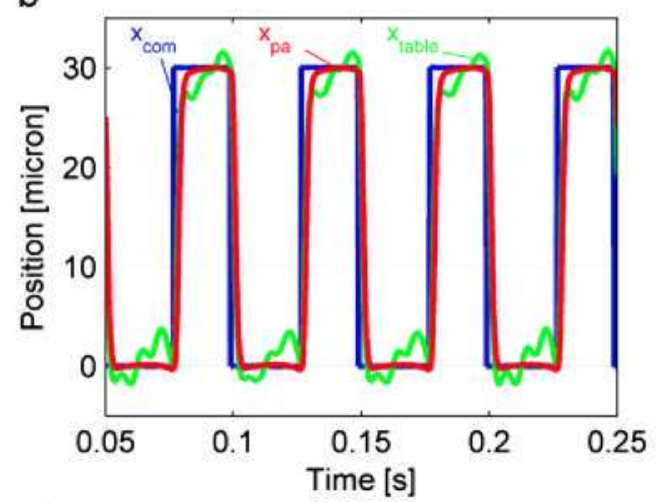

Cutting conditions:

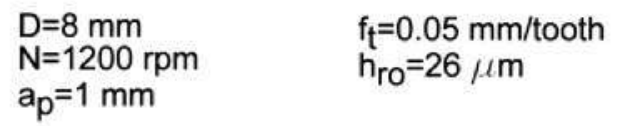

Fig. 10. Worktable performance: (a) simulation and (b) experiment.

\section{Acknowledgements}

The authors would like to thank the financial support received from the Spanish Ministry of Education and Science to this research project, CICYT DPI 2005-08932. Mr. Diez is supported by a Doctoral Scholarship from the Chilean Republic and a Doctoral Scholarship from Fundación Carolina in Spain.

\section{References}

[1] S. Spiewak, An improved model of the chip thickness in milling, CIRP Annals-Manufacturing Technology 44 (1995) 39-42.

[2] W.A. Kline, R.E. DeVor, The effect of runout on cutting geometry and forces in end milling, International Journal of Machine Tool Design and Research 23 (1983) $123-140$.

[3] J.-J. Wang, S.Y. Liang, Chip load kinematics in milling with radial cutter runout, Transactions of the ASME Journal of Engineering for Industry 118 (1996) 111-116.

[4] S.Y. Liang, J.J. Wang, Milling force convolution modeling for identification of cutter axis offset, International Journal of Machine Tools and Manufacture 34 (1994) 1177-1190.

[5] J-J.J. Wang, C.M. Zheng, Identification of cutter offset in end milling without a prior knowledge of cutting coefficients, International Journal of Machine Tools and Manufacture 43 (2003) 687-697.
[6] R.J. Seethaler, I. Yellowley, The identification of radial runout in milling operations, Transactions of the ASME Journal of Manufacturing Science and Engineering 121 (1999) 524-531.

[7] W.Y. Bao, I.N. Tansel, Modeling micro-end-milling operations. Part II: tool run-out, International Journal of Machine Tools and Manufacture 40 (2000) 2175-2192.

[8] T.L. Schmitz, J. Couey, E. Marsh, N. Mauntler, D. Hughes, Runout effects in milling: surface finish, surface location error, and stability, International Journal of Machine Tools and Manufacture 47 (2007) 841-851.

[9] K.A. Hekman, S.Y. Liang, In-process monitoring of end milling cutter runout, Mechatronics 7 (1997) 1-10.

[10] T. Insperger, B.P. Mann, T. Surmann, G. Stépán, On the chatter frequencies of milling processes with runout, International Journal of Machine Tools and Manufacture 48 (2008) 1081-1089.

[11] M. Wan, W.H. Zhang, J.W. Dang, Y. Yang, A unified stability prediction method for milling process with multiple delays, International Journal of Machine Tools and Manufacture 50 (2010) 29-41.

[12] M. Arizmendi, J. Fernández, A. Gil, F. Veiga, Model for the prediction of heterogeneity bands in the topography of surfaces machined by peripheral milling considering tool runout, International Journal of Machine Tools and Manufacture 50 (2010) 51-64.

[13] K.A. Desai, P.K. Agarwal, P.V.M. Rao, Process geometry modeling with cutter runout for milling of curved surfaces, International Journal of Machine Tools and Manufacture 49 (2009) 1015-1028.

[14] S.Y. Liang, S.A. Perry, In-process compensation for milling cutter runout via chip load manipulation, Transactions of the ASME Journal of Engineering for Industry 116 (1994) 153-160.

[15] S. Sastry, S.G. Kapoor, R.E. DeVor, Compensation of progressive radial run-out in face-milling by spindle speed variation, International Journal of Machine Tools and Manufacture 40 (2000) 1121-1139.

[16] F.M. Kolartis, W.R. DeVries, A mechanistic dynamic model of end milling for process controller simulation, Transactions of the ASME Journal of Engineering for Industry 113 (1991) 176-183.

[17] A.T. Elfizy, G.M. Bone, M.A. Elbestawi, Design and control of a dual-stage feed drive, International Journal of Machine Tools and Manufacture 45 (2005) 153-165.

[18] H. Pérez, J. Rios, E. Díez, A. Vizán, Increase of material removal rate in peripheral milling by varying feed rate, Journal of Materials Processing Technology 201 (2008) 486-490.

[19] M. Wan, W.H. Zhang, Systematic study on cutting force modelling methods for peripheral milling, International Journal of Machine Tools and Manufacture 49 (2009) 424-432.

[20] H.Z Li, X.P. Li, A numerical study of the effects of cutter runout on milling process geometry based on true tooth trajectory, The International Journal of Advanced Manufacturing Technology 25 (2004) 435-443.

[21] E.J. Armarego, N.P. Deshpande, Computerized end-milling force predictions with cutting models allowing for eccentricity and cutter deflections, CIRP Annals-Manufacturing Technology 40 (1991) 25-29.

[22] S. Tobias, Vibraciones en máquinas-herramientas, Ediciones URMO, Bilbao, 1972.

[23] S. Smith, J. Tlusty, Efficient simulation programs for chatter in milling, CIRP Annals-Manufacturing Technology 42 (1993) 463-466.

[24] Y. Altintas, in: Manufacturing automation: Metal cutting mechanics, Machine Tool Vibrations, and CNC, Cambridge University Press, Cambridge, 2000.

[25] Y. Altintaș, E. Budak, Analytical prediction of stability lobes in milling, CIRP Annals-Manufacturing Technology 44 (1995) 357-362.

[26] T. Insperger, J. Gradisek, M. Kalveram, G. Stépán, K. Weinert, E. Govekar, Machine tool chatter and surface quality in milling processes, in: Proceedings of IMECE'04, November 13-19, 2004.

[27] J. Gradisek, M. Kalveram, T. Insperger, K. Weinert, G. Stépán, E. Govekar, 1. Grabec, On stability prediction for milling, International Journal of Machine Tools and Manufacture 45 (2005) 769-781.

[28] E. Budak, Analytical models for high performance milling. Part II: process dynamics and stability, International Journal of Machine Tools and Manufacture 46 (2006) 1489-1499.

[29] A.M. Gouskov, S.A. Voronov, H. Paris, S.A. Batzer, Nonlinear dynamics of a machining system with two interdependent delays, Communications in Nonlinear Science and Numerical Simulation 7 (2002) 207-221.

[30] X. Long, B. Balachandran, B.P. Mann, Dynamics of milling processes with variable time delays, Nonlinear Dynamics 47 (2007) 49-63.

[31] L.F. Shampine, Solving delay differential equations with dde23, 2002. Available from: <http://www.mathworks.com/matlabcentral/fileexchange/ 3899>.

[32] M. Pozzi, T. King, Piezoelectric actuators in micropositioning, The IEE Engineering Science and Educational Journal 10 (2001) 31-36.

[33] H. Pérez, A. Vizán, J.C. Hernandez, M. Guzmán, Estimation of cutting forces in micromilling through the determination of specific cutting pressures, Journal of Materials Processing Technology 190 (2007) 18-22. 